\title{
Fine Needle Aspiration Cytology (FNAC) of Neoplasms in Dogs and Cats, with Emphasis on Differential Diagnosis - A Retrospective Study
}

\author{
Geta PAVEL, Razvan MĂLĂNCUŞ*, Mihai CONDREA \\ ${ }^{1}$ Department of Physiology and Pathophysiology, University of Agricultural Sciences and Veterinary \\ Medicine, Iasi. \\ *Corresponding author: razvanmalancus@gmail.com
}

Bulletin UASVM Veterinary Medicine 73(1) / 2016,

Print ISSN 1843-5270; Electronic ISSN 1843-5378

DOI:10.15835/buasvmcn-vm: 11815

\begin{abstract}
Fine needle aspiration cytology (FNA) is a fast, noninvasive method, widely used by clinical laboratories to diagnose neoplasms before the surgical intervention. FNA can be used for obtaining a tissue diagnosis of subcutaneous and other tumors and also for body cavity effusions. This study proposes an evaluation of the types of neoplasms and malignancy criteria found in cytological samples obtained from dogs and cats. The study was conducted at the Faculty of Veterinary Medicine of Iasi between 2012 and 2014 on 23 dogs and 15 cats. Patients diagnosed with masses and body cavity effusions by the pathologists from Internal Medicine and Radiology Clinic were referred to further assessment. Routine FNAC was performed by the attending pathologist. The cytological samples were obtained by fine needle aspiration in order to establish the cellular origin of the neoplasms. Of 67 samples of fine needle aspiration, 38 (56,7 \%) specimens were diagnosed as neoplasms, 23 (60,5 \%) being obtained from dogs and 15 (39,5\%) from cats. Based on cytological malignancy criteria were diagnosed with certainty a number of 18 (47.4\%) neoplasms represented by: adenocarcinoma - 4 cases (three cases with pulmonary origin and one with mammary origin), cutaneous mastocytoma - 3 cases, osteosarcoma - 3 cases, lymphoma and lymphosarcoma - 2 cases, liposarcoma - 1 case, hemangiosarcoma - 2 cases, leukemia - 2 cases and hemophagocytic histiocytic sarcoma in one case. For the rest of the samples the cell type was not established, being recommended further histopathological examination in order to provide a certain diagnosis. The results of this study confirmed FNAC as a reliable and useful diagnostic procedure for neoplastic masses. Even though FNAC has a limited value in determining the cellular origin of tumoral masses or malignant effusions, it often provides a definitive diagnosis or can narrow the list of differentials.
\end{abstract}

Keywords: fine-needle aspiration cytology (FNAC), neoplasia, malignancy criteria

\section{INTRODUCTION}

Fine needle aspiration cytology (FNA) is a fast, noninvasive method, widely used by clinical laboratories to diagnose neoplasms before the surgical intervention. FNA can be used for obtaining a tissue diagnosis of subcutaneous and other tumors and also for body cavity effusions (North and Banks, 2009).

FNA is highly cost effective and accurate as a first line investigative technique with differential diagnoses including reactive hyperplasia/inflammatory conditions, granulomatous disorders and malignancy, for cases requiring further investigations, surgical intervention or clinical follow-up. FNA requires readily available equipment, takes very little time to perform, causes minimal trauma and may be repeated if required. As an investigative technique it is acceptable to most patients and it rapidly provides a diagnosis 
on which to base further management (Dey, 2007; Sharkey, 2014).

Cytology refers to the microscopic evaluation of cells. Cytological evaluation can be very useful in the clinical diagnosis of neoplasia. Samples for cytology can be collected from a wide variety of sites and many different tissues. Sample collection is relatively noninvasive, and most samples can be collected on an outpatient basis. Both sample collection and specimen preparation can be performed using inexpensive equipment that is readily available in most veterinary practices. Inhouse interpretations can be made the same day, and interpretations from reference laboratories frequently are available within 24 hours. Complications of sample collection for cytological evaluation are uncommon and usually are limited to minor hemorrhage. Infection, injury to adjacent structures, and dissemination of neoplastic cells are extremely uncommon (Cowell et al., 1998; North and Banks, 2009).

This study proposes an evaluation of the types of neoplasms and malignancy criteria found in cytological samples obtained from dogs and cats.

\section{MATERIALS AND METHODS}

The study was conducted at the Faculty of Veterinary Medicine of Iasi between 2012 and 2014 on 23 dogs and 15 cats. Patients diagnosed with masses and body cavity effusions by the pathologists from Internal Medicine and Radiology Clinic were referred to further assessment. The cytological samples were obtained by fine needle aspiration in order to establish the cellular origin of the neoplasms. The FNA specimens were obtained as previously described (Frable, 1983). The air-dried smears were immediately prepared and stained by MGG (May-Grünwald-Giemsa) or Diff-Quick method, as previously described (Cowell and Tyler, 1998). The cytological specimens obtained over a two-year period from superficial and deep neoplastic masses and body cavity effusions were retrospectively evaluated. The definitive or differential diagnosis was based on the alterations observed on the smear taking into account the cytological malignancy criteria.

\section{RESULTS AND DISCUSSION}

Of 67 samples of fine needle aspiration, 38 (56.7 \%) specimens were diagnosed as neoplasms,
$23(60.5 \%)$ being obtained from dogs and 15 $(39.5 \%)$ from cats.

Table 1 presents the cytology results of the FNA samples obtained from the superficial masses (cutaneous, subcutaneous, mammary), hypertrophied lymph nodes (mandibular, axillar, popliteal and inguinal) deep masses (spleen, lungs, kidneys, mediastinum, bone), from the body cavity effusion (pleural, peritoneal and pericardial) and also from the leukemic blood samples of investigated dogs and cats.

Based on cytological malignancy criteria were diagnosed with certainty a number of 18 neoplasms (47.4 \%) represented by: adenocarcinoma - 4 cases (three cases with pulmonary origin and one with mammary origin), cutaneous mastocytoma - 3 cases, osteosarcoma - 3 cases (2 extraskeletal osteosarcoma), lymphoma and lymphosarcoma 2 cases, liposarcoma - 1 case, hemangiosarcoma - 2 cases, leukemia - 2 cases and hemophagocytic histiocytic sarcoma in one case. For the rest of the samples (20) the cell type was not established, however, it has been determined the orientation for the cytological diagnosis, has been considered the differential or associated diagnosis and has also been recommended further histopathological examination in order to provide a certain diagnosis.

According to Table 1 data, in neoplasm affected dogs, the malignant cytological diagnosis was definitive in $52,2 \%$ of the cases and uncertain in $47.8 \%$, while in cats, accurate diagnosis established by cytology has been noted in only $40 \%$ of cases, while the other $60 \%$ required complementary investigations. Neoplasia associated lesions were consistent with hemorrhagic lesions in $50 \%$ of cases and inflammations and necrosis in the rest of $55.3 \%$.

The malignancy criteria that led to the cytological diagnosis (Allen et al., 1986; Meachem et al., 2012, Menard et al., 1986; North and Banks, 2009; Sharkey and Wellman, 2011; Wellman, 1990) were represented by: cellular criteria (anisocytosis, macrocytosis, pleomorphism, varying of the differentiation stages, variation in nuclear to cytoplasmic (N/C) ratio, loss of intercellular cohesion, atypical cellular forms), cytoplasmic criteria (high N/C ratio, cytoplasmic basophilia, cytoplasmic microvacuolization) and nuclear criteria (anisokaryosis, macronuclei, multinuclearity with atypical shape and size nuclei, frequent mitosis, abnormal mitotic figures, 
Tab. 1. Results obtained after cytological examination of the samples

\begin{tabular}{|c|c|c|c|c|c|c|c|c|c|c|}
\hline \multirow{2}{*}{\multicolumn{2}{|c|}{ Cytological Diagnosis Cytological Sample }} & \multicolumn{2}{|c|}{ Subjects } & \multicolumn{4}{|c|}{$\begin{array}{c}\text { Cytological malignancy } \\
\text { evaluation }\end{array}$} & \multirow{3}{*}{$\begin{array}{c}\text { Associated } \\
\text { inflammation/ } \\
\quad \text { necrosis }\end{array}$} & \multirow{3}{*}{$\begin{array}{l}\text { Associated } \\
\text { hemorrhagic } \\
\text { lesions }\end{array}$} & \multirow{3}{*}{$\begin{array}{c}\text { Differential/ } \\
\text { associated diagnosis }\end{array}$} \\
\hline & & \multirow{2}{*}{ Dogs } & \multirow{2}{*}{ Cats } & \multicolumn{2}{|c|}{ Definitive } & \multicolumn{2}{|c|}{ Suspicion } & & & \\
\hline & & & & Dogs & Cats & Dogs & Cats & & & \\
\hline $\begin{array}{c}\text { Cutaneous } \\
\text { mastocytoma }\end{array}$ & Cutaneous mass & 3 & - & 3 & - & - & - & - & 2 & - \\
\hline $\begin{array}{c}\text { Subcutaneous } \\
\text { hemangiosarcoma } \\
\text { (HAS) }\end{array}$ & $\begin{array}{l}\text { Subcutaneous } \\
\text { mass }\end{array}$ & - & 1 & - & 1 & - & - & - & 1 & - \\
\hline $\begin{array}{l}\text { Subcutaneous } \\
\text { osteosarcoma }\end{array}$ & $\begin{array}{c}\text { Subcutaneous } \\
\text { mass }\end{array}$ & - & 1 & - & 1 & - & - & 1 & - & - \\
\hline $\begin{array}{c}\text { Mammary } \\
\text { adenocarcinoma }\end{array}$ & Mammary gland & 1 & - & 1 & - & - & - & - & - & - \\
\hline Liposarcoma & $\begin{array}{c}\text { Subcutaneous } \\
\text { mass }\end{array}$ & 1 & - & 1 & - & - & - & - & - & - \\
\hline $\begin{array}{l}\text { Multicentric } \\
\text { lymphoma }\end{array}$ & $\begin{array}{c}\text { Popliteal } \\
\text { lymphnode }\end{array}$ & 1 & - & 1 & - & - & - & - & 1 & - \\
\hline $\begin{array}{c}\text { Lymphoblastic } \\
\text { lymphosarcoma }\end{array}$ & $\begin{array}{l}\text { Inguinal } \\
\text { lymphnode }\end{array}$ & 1 & - & - & - & 1 & - & 1 & - & Malignant mastocytoma \\
\hline $\begin{array}{l}\text { Lymphocytic } \\
\text { lymphosarcoma }\end{array}$ & $\begin{array}{l}\text { Mandibulary/ } \\
\text { Axillary } \\
\text { lymphnode } \\
\end{array}$ & 1 & 1 & 1 & - & - & 1 & - & - & $\begin{array}{c}\text { Liposarcoma/ } \\
\text { postvaccinal sarcoma/ } \\
\text { Fibrosarcoma } \\
\end{array}$ \\
\hline Osteosarcoma (OS) & Humerus & 2 & - & 1 & - & 1 & - & 1 & 2 & Liposarcoma \\
\hline Mediastinal OSE & Mediastinal mass & 1 & - & 1 & - & - & - & 1 & 1 & Chondrosarcoma \\
\hline Splenic histiocytoma & Spleen & 1 & - & - & - & 1 & - & 1 & 1 & $\begin{array}{c}\text { Splenic myeloid } \\
\text { metaplasia }\end{array}$ \\
\hline $\begin{array}{c}\text { Pulmonary } \\
\text { adenocarcinoma }\end{array}$ & Pulmonary mass & 1 & - & 1 & - & - & - & 1 & - & - \\
\hline Cystic renal tumor & Renal mass & - & 1 & - & - & - & 1 & - & 1 & Benign renal cyst \\
\hline Palate tumor & Sessile tumor & - & 1 & - & - & - & 1 & 1 & 1 & Sarcoma/mycosis \\
\hline $\begin{array}{c}\text { Pulmonary } \\
\text { adenocarcinoma }\end{array}$ & Pleural effusion & 4 & 2 & - & 2 & 4 & - & 4 & 1 & $\begin{array}{c}\text { Pleuropneumonia/ } \\
\text { mesothelioma }\end{array}$ \\
\hline Pulmonary metastasis & Pleural effusion & 1 & 5 & - & - & 1 & 5 & 5 & 2 & $\begin{array}{c}\text { Mammary } \\
\text { adenocarcinoma/ } \\
\text { Granular lymphoma/B } \\
\text { lymphoma/ } \\
\text { Plasmocitoma/ } \\
\text { Mesothelial hiperplasia } \\
\end{array}$ \\
\hline Splenic metastasis $\mathrm{P}$ & Peritoneal effusion & 2 & - & - & - & 2 & - & 2 & 2 & $\begin{array}{c}\text { Mammary } \\
\text { adenocarcinoma/ } \\
\text { Multicentric } \\
\text { lymphoma/ Mesothelial } \\
\text { hiperplasia } \\
\end{array}$ \\
\hline Liver adenocarcinoma $\mathrm{P}$ & Peritoneal effusion & - & 1 & - & - & - & 1 & 1 & 1 & PIF \\
\hline $\begin{array}{c}\text { Pericardial } \\
\text { hemangiosarcoma }\end{array}$ & $\begin{array}{l}\text { Pericardial } \\
\text { effusion }\end{array}$ & 2 & - & 1 & - & 1 & - & - & 2 & $\begin{array}{l}\text { Epithelioid } \\
\text { mesothelioma/ } \\
\text { Epithelioid HAS }\end{array}$ \\
\hline $\begin{array}{c}\text { Hemophagocytic } \\
\text { histiocytic sarcoma }\end{array}$ & $\begin{array}{l}\text { Pericardial } \\
\text { effusion }\end{array}$ & - & 1 & - & 1 & - & - & 1 & 1 & Chemodectoma \\
\hline $\begin{array}{c}\text { Lymphoblastic } \\
\text { leukemia }\end{array}$ & Blood & 1 & - & 1 & - & - & - & - & - & - \\
\hline Mielocytic leukemia & Blood & - & 1 & - & 1 & - & - & 1 & - & - \\
\hline Total ca & ases & 23 & 15 & 12 & 6 & 11 & 9 & 21 & 19 & \\
\hline$\%$ & & & & 52.2 & 40.0 & 47.8 & 60.0 & 55.3 & 50.0 & \\
\hline
\end{tabular}


variable number and form nucleoli, macronucleoli, chromatin dense granularity, abnormal distribution of chromatin).

In this study, common cellular malignant features of all solid superficial or deep masses and also of body cavity fluids have been highlighted (Tab. 2 and 3).

For the cutaneous, subcutaneous and mammary masses, 3 cases of mastocytoma were diagnosed in dogs (three Sharpei, Amstaff and Poodle females, of 3, 4 and 18 years old), a mammary adenocarcinoma in a 16 years old Pekingese female and a liposarcoma in a 5 years old Poodle male, while in cats, a subcutaneous osteosarcoma $(1,5$ years old, Persian cat) and a feline subcutaneous hemophagocytic hemangiosarcoma (11 years old, European shorthair cat). Malignancy criteria that led to the diagnosis were: cellular pleomorphism (7/7), anisokaryosis and anisocytosis (7/7), high $\mathrm{N} / \mathrm{C}$ ratio (4/7), variable $\mathrm{N} / \mathrm{C}$ ratio $(3 / 7)$, multinuclearity (5/7), clustered, unevenly distributed chromatin (2/7), multiple, unequal nucleoli

Tab. 2. Comparative malignancy cytological criteria for cutaneous/mammary solid masses and hyperplasic lymph nodes in dogs and cats diagnosed with neoplasia

\begin{tabular}{|c|c|c|c|c|c|}
\hline \multirow{2}{*}{ No. } & \multirow{2}{*}{ Criteria } & \multicolumn{2}{|c|}{$\begin{array}{c}\text { Solid masses } \\
4 \mathrm{CNM} / 1 \mathrm{CCM} / 2 \mathrm{MNM}\end{array}$} & \multicolumn{2}{|c|}{$\begin{array}{c}\text { Hyperplasic lymph nodes } \\
2 \text { GLAM/2 LAML }\end{array}$} \\
\hline & & $\begin{array}{c}\text { Dogs } \\
4 \mathrm{~F} \text { and1 } \mathrm{M} \\
\end{array}$ & $\begin{array}{l}\text { Cats } \\
2 \mathrm{~F}\end{array}$ & $\begin{array}{c}\text { Dogs } \\
3 \mathrm{~F} \\
\end{array}$ & $\begin{array}{l}\text { Cats } \\
1 \mathrm{~F}\end{array}$ \\
\hline 1. & Cellular pleomorphism & $5 / 5$ & $2 / 2$ & - & 1 \\
\hline 2. & Anisocytosis/anisokaryosis & $5 / 5$ & $2 / 2$ & $3 / 3$ & $1 / 1$ \\
\hline 3. & High N/C ratio & $3 / 5$ & $1 / 2$ & - & - \\
\hline 4. & Variable $\mathrm{N} / \mathrm{C}$ ratio & $2 / 5$ & $1 / 2$ & $3 / 3$ & $1 / 1$ \\
\hline 5. & Multinuclearity & $4 / 5$ & $1 / 2$ & - & $1 / 1$ \\
\hline 6. & Frequent mitoses & - & - & $1 / 3$ & - \\
\hline 7 & Asymmetrical/anomalous mitoses & - & - & $1 / 3$ & - \\
\hline 8 & Dense chromatin & $2 / 5$ & - & $1 / 3$ & - \\
\hline 9 & Multiple, unequal nucleoli & $2 / 5$ & $1 / 2$ & $2 / 3$ & - \\
\hline 10 & Macronucleoli & $2 / 5$ & $1 / 2$ & $2 / 3$ & - \\
\hline
\end{tabular}

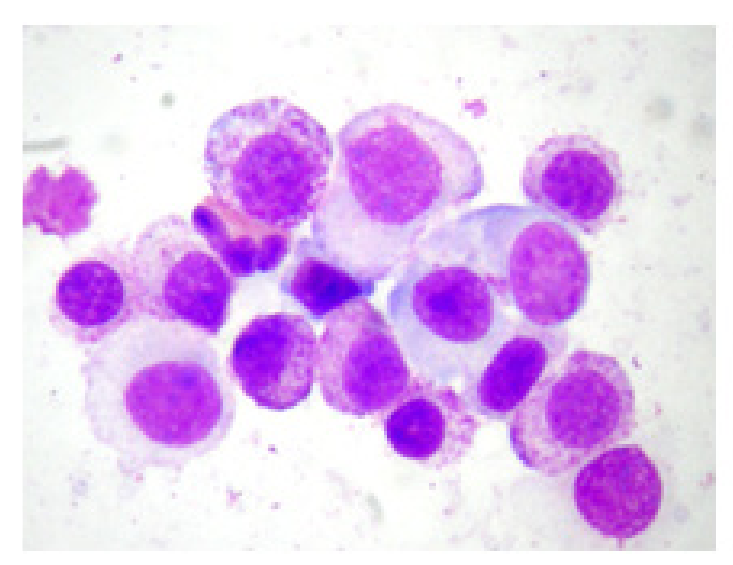

Fig. 1. Sharpei, 3 years old. FNA Prescapular lymph node. Poorly differentiated mastocytoma: immature mast cells with small-sized granules in cytoplasm, anisocytosis, anisokaryosis, a binucleated cell, an eosinophil among the mast cells, MGG, x 1000.

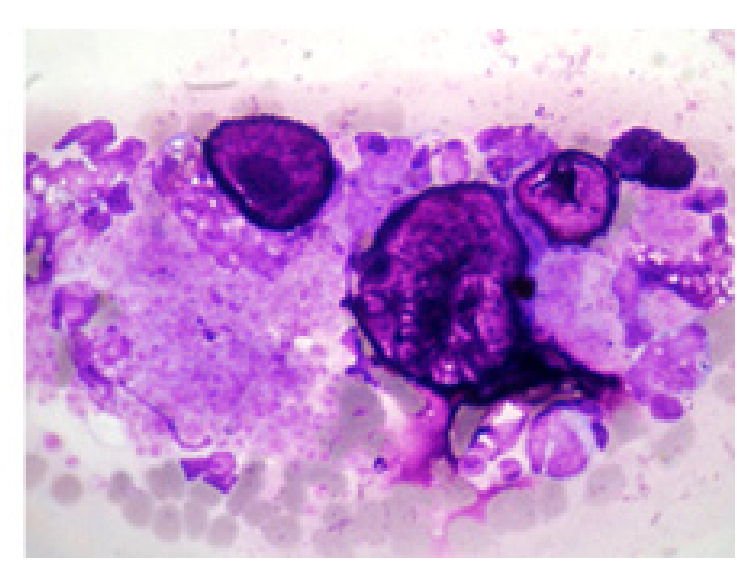

Fig. 2. Caniche, 18 years old, F.

FNA metatarsal mass. Well differentiated mastocytoma: group of hypergranulated mast cells, anisocytosis, macrocytosis, macronuclei, high $\mathrm{N} / \mathrm{C}$ ratio, hemorrhagic background: erythrocytes, platelets, inflammatory cells, neutrophils, eosinophils, MGG, x 1000. 
(3/7) and macronucleoli (3/7). In all cases of cutaneous neoplasms, mitoses were rare or absent (Tab. 2).

Canine mastocytoma presented different locations (in the ear, rapidly spreading to the cervical and prescapular lymph nodes; metatarsus, with fistulization; mammary gland and vulvar region) and was definitively diagnosed based on cytological characteristics: many mast cells, hypo- or hypergranulation with visible nuclei, macronucleoli and with fine grit in case of poorly differentiated mastocytoma (Fig. 1) and hypochromatic, poorly visible nucleus, covered with metachromatic grit in case of well differentiated mastocytoma (Fig. 2). In all cases, the eosinophilic infiltration has been observed (the eosinophils were present).

It is well documented that FNA cytology gives a diagnosis for $92-96 \%$ of mast cell tumours. Mast cells readily exfoliate and are easily identifiable by metachromatically staining intracytoplasmic granules (Blackwood et al, 2012).

Mammary adenocarcinoma cytological diagnosis in dogs was established based on the acinar arrangement of the hyperplasic epithelialglandular cells, pronounced anisokaryosis and anisocytosis, presence of multinucleated cells, irregular chromatin pattern, presence of 1-4 unequal nucleoli. In the case diagnosed in this study, the radiological examination also revealed lung metastases, as frequently cited by other authors. Although in this study we diagnosed one case of malignant mammary neoplasia, according to data from the literature, mammary neoplasia remains one of the most common clinical problems of adult female dogs, representing $50-70 \%$ of the

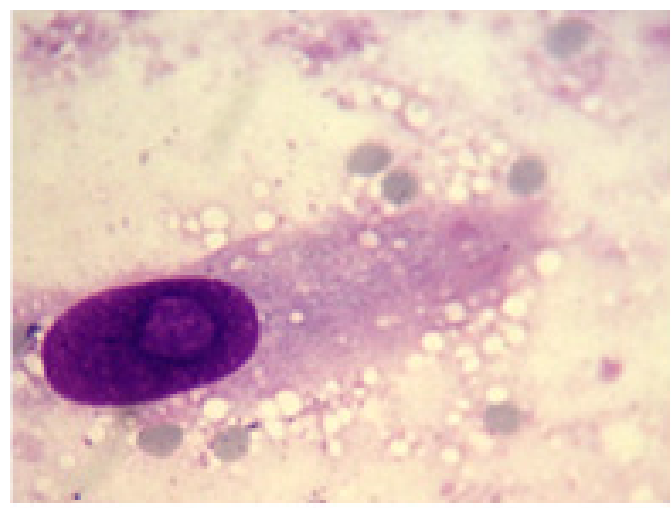

A diagnosed neoplasms in dogs (Allen et al., 1986; Murakami et al., 2000).

Among the canine cutaneous nodular masses, one was cytological diagnosed as liposarcoma in a 5 years old Poodle male. In the cutaneous mass (Fig. 3A), as in the prescapular lymph node (Fig. 3B) was revealed the presence of atypical lipoblasts with evident malignant characteristics: macronuclei, unevenly distributed, dense chromatin, macronucleoli, asynchrony between nucleus and cytoplasm. In lymph node, the lymphoid tissue was completely replaced by neoplastic fat tissue, a fact that has also been observed by other authors in other advanced metastatic neoplastic processes (Meyer and Harvey, 1998).

Subcutaneous osteosarcoma was diagnosed in a 1.5 years old Persian, female cat, revealing a subcutaneous masse in the scapular area and osteolysis in the cervical vertebral (C4-C7) region. Cytological examination revealed the presence of malignant osteoblasts, osteoclasts (Fig. 4A) and extracellular protein masses, representing the osteoid matrix, the main cytological diagnosis criteria of osteosarcomas, which allowed us to state a definitive diagnosis (Fig. 4B).

In osteosarcoma, independently on the location, gold standard for diagnosis is considered to be biopsy with histopathological evaluation, although fine-needle aspiration cytology of lytic lesions is gradually being used more frequently in veterinary medicine (Barger et al., 2005).

Subcutaneous hemangiosarcoma was diagnosed in a 11 years old cat presenting a purple, cystic formation in the cutaneous area of lower abdomen, from which a hemorrhagic, xanthochromic (after centrifugation) fluid was collected and examined

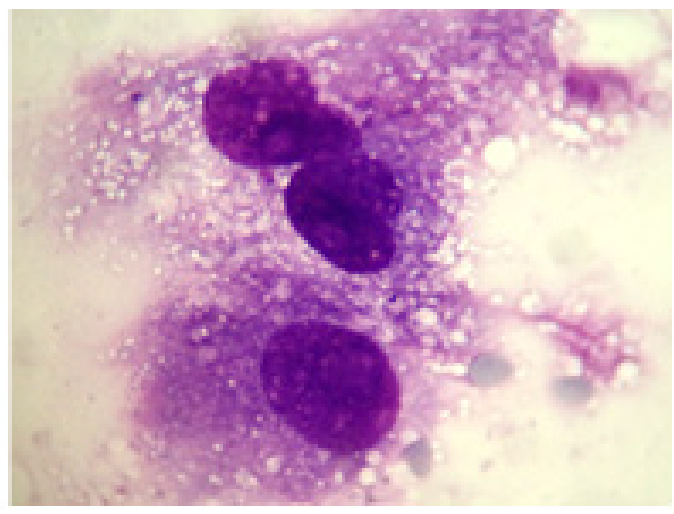

B

Fig. 3. Caniche, 5 years old, M. Liposarcoma: A. atypical lipoblast with macronucleolus, lipidic vacuoles and erythrocytes. B. atypical lipoblasts, unevenly distributed, dense chromatin, binucleated cells. MGG, x 1000. 
by cytology. Cytological examination revealed mesenchymal tissue cellular areas (predominantly fusiform), with moderate anisocytosis, but high $\mathrm{N} / \mathrm{C}$ ratio and rare bi- and multinucleated cells (Fig. $5 \mathrm{~A}$ ), along with hemosiderin and hematoidin-grit inside the macrophages and erythrophagocytosis phenomena (Fig. 5B).

Mesenchymal origin cells are generally weak exfoliative. Aspirates with low cellularity per microscopic field may suggest a tumor of mesenchymal origin (North and Banks, 2009).

Lymphoma and lymphosarcoma were diagnosed in 3 female dogs (two Cocker spaniels and one German Shepherd), aged between 6 and 12 years old, based on specific cell malignancy criteria: lymphoblasts predominance, presence of nuclear shadows (free, degenerated nuclei, due to blasts increased fragility), cellular monomorphism, moderate anisocytosis and anisokaryosis, variable $\mathrm{N} / \mathrm{C}$ ratio (in $3 / 3$ cases), multiple, unequal nucleoli and macronucleoli in 2/3 cases, an increased mitotic index in one case and the presence of atypical mitoses, also, in one case (Tab. 2). Although the presence of free cytoplasmic bodies is not a specific cellular phenomenon, the lymphocytic bodies were steadily observed in all the examined samples (Fig. 6). One case showed metachromatic grit background and rare inflammatory cells, so the mastocytoma differential diagnosis was considered.

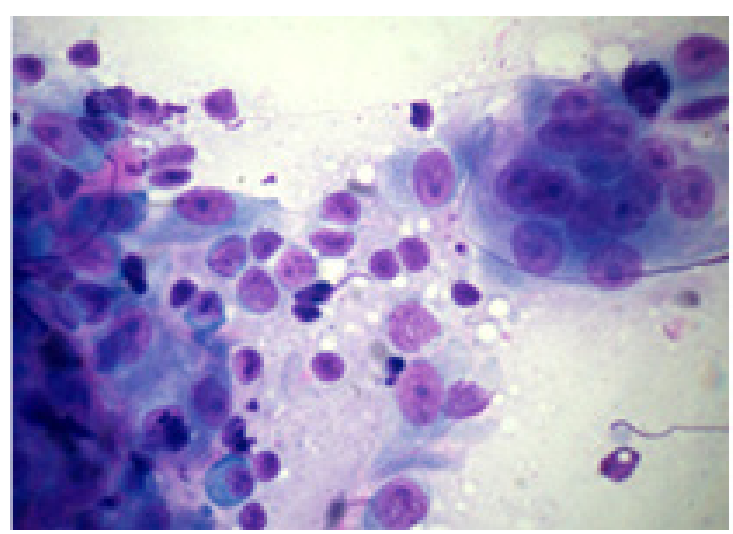

A

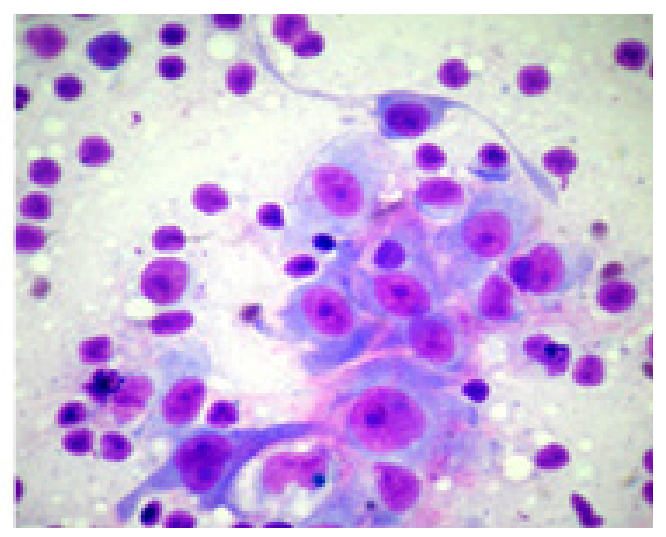

B

Fig. 4. Cat, Persian, 1,5 years old, F. Subcutaneous extraskeletal osteosarcoma FNA cutaneous neoplastic mass, inferior cervical region. A. Necrosis area - left, osteoblasts - center, osteoclast - right. Col. MGG, x 1000. B. Group of osteoblasts, anisocytosis, anisokaryosis, binucleated cells, macronucloeoli, osteoid extracellular protein matrix among the cells. Col. Diff-Quick, x 1000.

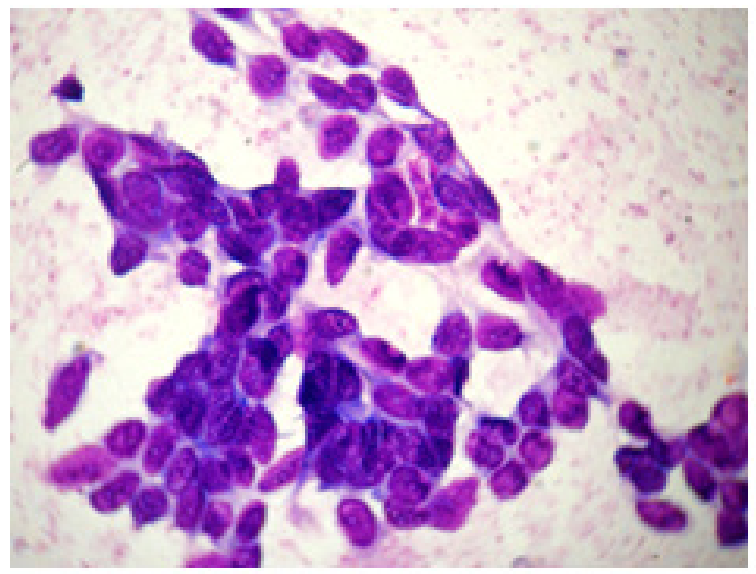

A

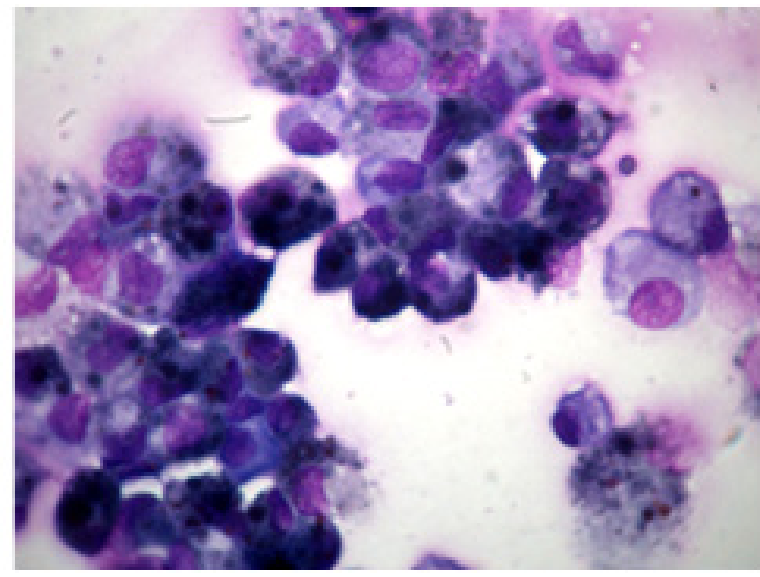

B

Fig. 5. Cat, European, 11 years old. Subcutaneous hemangiosarcoma. FNA cutaneous structure, abdomen (haemorrhagic liquid) A. Group of neoplastic mesenchymal cells. B. Group of macrophages with siderophagocytosis, hematoidine crystals, bilirubin. MGG, x 1000. 
The cytological diagnosis of lymphadenopathy, including that caused by lymphoid neoplasia, can be highly accurate. Knowledge of history and physical examination findings is useful in the cytological evaluation of lymphoid tissue. For example, immunization may cause diffuse paracortical hyperplasia to the extent that the lymphocytes may appear neoplastic. A dog with multiple peripheral lymph node enlargements is more likely to have lymphoma than a dog with a single enlarged lymph node. Young cats with enlarged peripheral lymph nodes may have

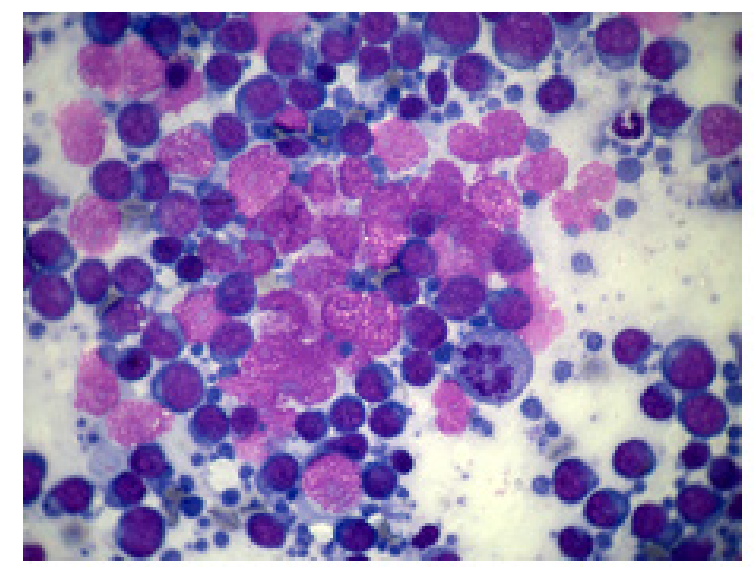

A non-neoplastic proliferative disease instead of lymphoma (Radin and Wellman, 2001).

The degree of differentiation and the classification of lymphoma may affect response to treatment and prognosis. A classification system of canine lymphomas based on the National Cancer Institute (NCI) Working Formulation of Non-Hodgkin's Lymphomas in humans has been described. The histologic classification is based on tissue architecture, cell morphology, and mitotic rate; the cytological classification is based almost entirely on nuclear characteristics including nuclear size, shape, and chromatin

Fig. 6. Cocker spaniel, M, 12 years old, Lymphoma. FNA popliteus lymph node. A. Lymphoid tissue: lymphocytes, atypical lymphoblasts, a mitosis. Background:Lymphoglandular bodies. B. atypical lymphocytes, three mitoses can be observated in the image, of which one is atypical; erythrocytic background. MGG, 1000.

Tab. 3. Comparative malignancy cytological criteria for deep neoplasms (cavities, organs, bones) and neoplastic liquids

\begin{tabular}{|c|c|c|c|c|c|}
\hline \multirow{2}{*}{ No } & \multirow{2}{*}{ Criteria } & \multicolumn{2}{|c|}{$\begin{array}{c}\text { Deep masses (7) } \\
1 \mathrm{MN} / 1 \mathrm{PN} / 1 \mathrm{RN} / 2 \mathrm{BN} / 1 \mathrm{SPN}\end{array}$} & \multicolumn{2}{|c|}{$\begin{array}{c}\text { Liquids (20) } \\
18 \mathrm{E} / 2 \mathrm{~B} \\
\end{array}$} \\
\hline & & $\begin{array}{c}\text { Dogs } \\
4 \mathrm{~F} \text { and } 1 \mathrm{M}\end{array}$ & $\begin{array}{c}\text { Cats } \\
1 \mathrm{~F} \text { and } 1 \mathrm{M}\end{array}$ & $\begin{array}{c}\text { Dogs } \\
15 \mathrm{~F} \text { and } 5 \mathrm{M} \\
\end{array}$ & $\begin{array}{c}\text { Cats } \\
6 \mathrm{~F} \text { and } 4 \mathrm{M}\end{array}$ \\
\hline 1. & Cellular pleiomorphism & $5 / 5$ & $2 / 2$ & $7 / 10$ & $7 / 10$ \\
\hline 2. & Anisocytosis/anisokaryosis & $5 / 5$ & $2 / 2$ & $7 / 10$ & $7 / 10$ \\
\hline 3. & High $\mathrm{N} / \mathrm{C}$ ratio & $3 / 5$ & $1 / 2$ & $2 / 10$ & - \\
\hline 4. & Variable $\mathrm{N} / \mathrm{C}$ ratio & $1 / 5$ & $1 / 2$ & $4 / 10$ & $3 / 10$ \\
\hline 5. & Multinuclearity & $4 / 5$ & $1 / 2$ & $6 / 10$ & $4 / 10$ \\
\hline 6. & Frequent mitoses & $2 / 5$ & - & $2 / 10$ & $2 / 10$ \\
\hline 7. & Asymmetrical/anomalous mitoses & $1 / 5$ & - & - & $2 / 10$ \\
\hline 8. & Dense, unequal chromatin & $2 / 5$ & - & $4 / 10$ & $4 / 10$ \\
\hline 9. & Multiple, unequal nucleoli & $3 / 5$ & $/ 2$ & $4 / 10$ & $2 / 10$ \\
\hline 10. & Macronucleoli & $2 / 5$ & $1 / 2$ & $5 / 10$ & $7 / 10$ \\
\hline
\end{tabular}

E- effusion; B - Blood: F - female; $\mathrm{M}$ - male. 
pattern and nucleolar number and size (Colomo et al., 2004). The majority of canine lymphomas are classified as high grade types and include lymphoblastic, immunoblastic, and diffuse small lymphoma. Diffuse large lymphoma has a medium to high mitotic rate and also might be considered aggressive (Meyer and Harvey, 1998).

In a 11 years old European female cat, the FNA of the hypertrophied axillary lymph node revealed hypocelularity with rare lymphocytes and absent lymphoblasts, but with the presence of some atypical mesenchymal cells with evident pleomorphism (star-shaped, oval, fusiform cells), some binucleated, while other multinucleated, with cytoplasmic vacuolization and adjacent lipid droplets. The established diagnosis was of mesenchymal neoplasm but the cellular type was not determined with certainty, with differential diagnosis of fibrosarcoma, liposarcoma and post vaccinal sarcoma being all considered.

After North and Banks, 2009, sarcomas are usually disseminated through blood, only the aggressive ones involving the regional lymph nodes. These represent the first dissemination site of other neoplastic types (mast cell tumors, epithelial tumors, melanomas).

Deep neoplastic masses in cavities, organs and bones were highlighted by radiological or ultrasound examination, the FNA samples being obtained by ultrasound-guided puncture. Five dogs aged 4 to 11 years (of which three Rottweillers, one Wirehaired Brac and one Cocker Spaniel) presented neoplastic masses in the

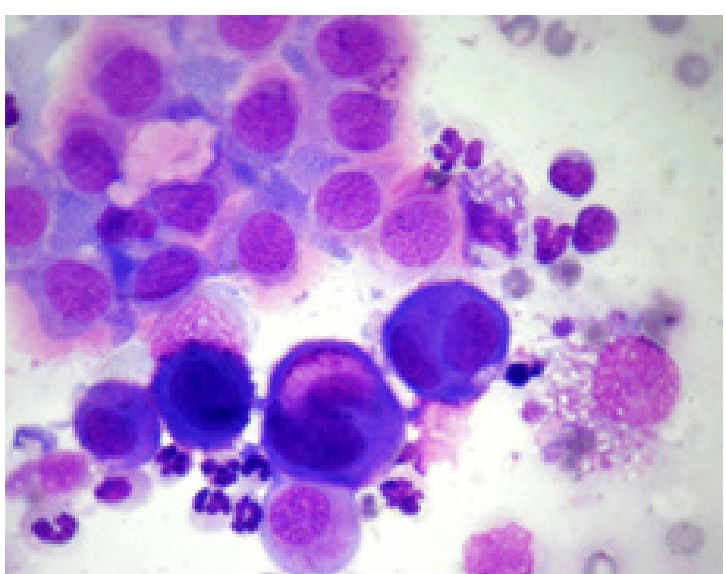

A anterior mediastinum, in lungs, in spleen and osteolysis areas in the forelimb region. Based on the malignancy criteria presented in Table 3, three osteosarcomas (OS) were diagnosed for the Rotweiller dogs, one extraskeletal mediastinal OS, one pulmonary adenocarcinoma and one splenic histiocytoma. The extraskeletal OS was initially diagnosed as a mesenchymal neoplasm due the mesenchymal cells important pleomorphism - oval, spherical, stellate - being necessary to differentiate between fibrosarcoma, osteosarcoma and extraskeletal chondrosarcoma. The presence of the extracellular osteoid matrix has shifted the diagnosis to OS (Fig. 7), confirmed later by histopathologic examination after euthanasia. Also, the pulmonary adenocarcinoma has been diagnosed based on the presence of the bronchoalveolar cells placards, with evident malignant characteristics (Fig. 8). One of the extraskeletal OS cases could not be diagnosed with certainty due to the presence of some lipoblasts associated degenerated mesenchymal cells beside the atypical osteoclasts (differential diagnosis between OS and liposarcoma).

Cytologically, OS can appear similar to chondrosarcoma, synovial cell sarcoma, and fibrosarcoma. Each of these tumors can have comparable cytologic features including eccentric nuclei and an extracellular eosinophilic matrix. The diagnostic power of cytology would likely be improved with alkaline phosphatase (ALP) staining to differentiate OS from other tumors that produces osteoid (Barger et al., 2005).

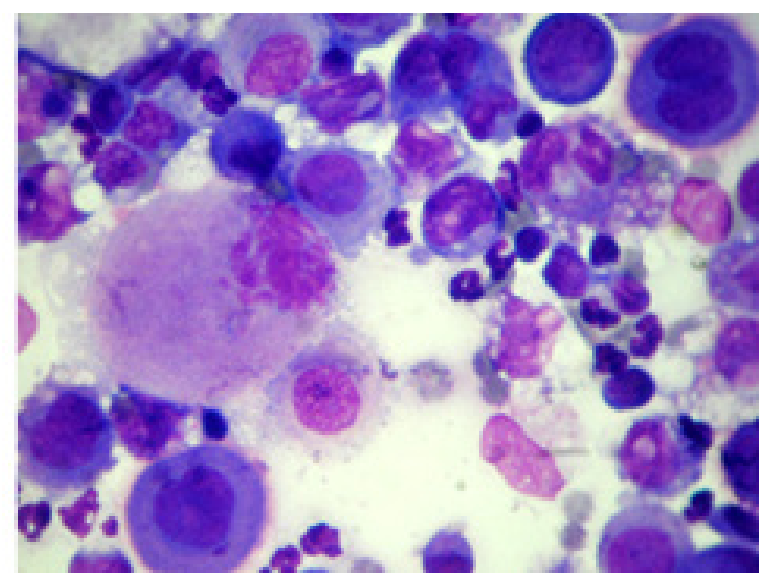

B

Fig. 7. Rottweiler, 4 years old, F. FNA mediastinal mass (hemorrhagic liquid).

Extraskeletal osteosarcoma: A. Group of osteoblasts with eosinophilic osteoid matrix in the extracellular space, bi- and multinucleated cells, anisokaryosis; hemorrhagic and inflammatory background. B. Atypical osteoblasts, asymmetrical mitoses. MGG, x 1000. 
Ina17years oldfemalecatarenalcysticneoplasm was diagnosed and differentiated to the benign neoplastic cyst, and in a 4 years old male cat a sessile structure was identified at the base of the tongue, on the soft palate and was cytological diagnosed as a mesenchymal neoplasm due to mesenchymal cells pleomorphism, but the inflammatory reaction and the presence of cytophagocytosis and of phagocytized hyphae required to differentiate from an inflammatory process with mycoses giant cells.

Unlike the superficial neoplastic masses, the neoplasms with internal location diagnosed by cytology showed frequent mitoses, including mitotic aberrations (3/7) and have been frequently associated with inflammation and necrosis.

The malign effusions diagnosed in the present study were represented by 12 pleural effusions ( 5 collected from dogs and 7 from cats), 3 peritoneal effusions ( 2 in dogs and one in a cat), and three pericardial effusions ( 2 in dogs and one in a cat). In addition, two more blood samples taken from one dog and one cat had been diagnosed with leukemia.

Neoplastic effusions from 9 dogs $(5$ males and 4 females), aged between 1.5 and 14 years were not diagnosed with certainty by cytology, excepting for one pericardial effusion. Following the cellular malignancy evaluation of the cavity effusions, four pleuro-pulmonary adenocarcinomas, 2 mammary adenocarcinoma metastases (lung, spleen), 1 multicentric lymphoma and 2 pericardial hemangiosarcoma were suspected, one of the last category being diagnosed with certainty. The examined liquids were mostly sero-hemorrhagic or hemorrhagic $(8 / 9)$, and in terms of the total number of nucleated cells (TNC), 4 were considered transudates (TNC between 0.345 and $558 \times 103$ / $\mathrm{mm} 3$ ), 2 exudates (12.35, respectively 14.85 nucleated cells $\times 10^{3} / \mathrm{mm}^{3}$ ) and 3 uncategorized. The predominant malignancy criteria were (Table 3): pleomorphism, respectively anisokaryosis and anisocytosis of the cell populations organized in large placards (carcinoma, adenocarcinoma, mesothelioma) or isolated without adhesions (lymphoma, hemangiosarcoma) - 7/10, multinuclearity - 6/10, the presence of multiple and unequal nucleoli - 4/10 and macronucleoli 5/10, dense uneven chromatin - 4/10 and less the presence of frequent mitoses - 2/10.

According to data cited by other authors, numerous errors in cytological diagnosis of neoplasia are made between carcinoma and mesothelioma, especially in those cases with associated mesothelial hyperplastic reactions (Cakir et al., 2009). Neoplastic cells organized in placards are shown in Figure 10, that may be consistent with carcinoma (Fig. 9A), but isolated cells appear as neoplastic mesothelial cells (Fig. 9B).

Reactive mesothelial cells may closely resemble cells from malignant neoplasms and are characterized by increased basophilia, variation in cell size, binucleation or multinucleation, and frequent mitoses. Reactive mesothelial cells may occur in large clusters, which also is characteristic of some malignant neoplasms. Unfortunately,

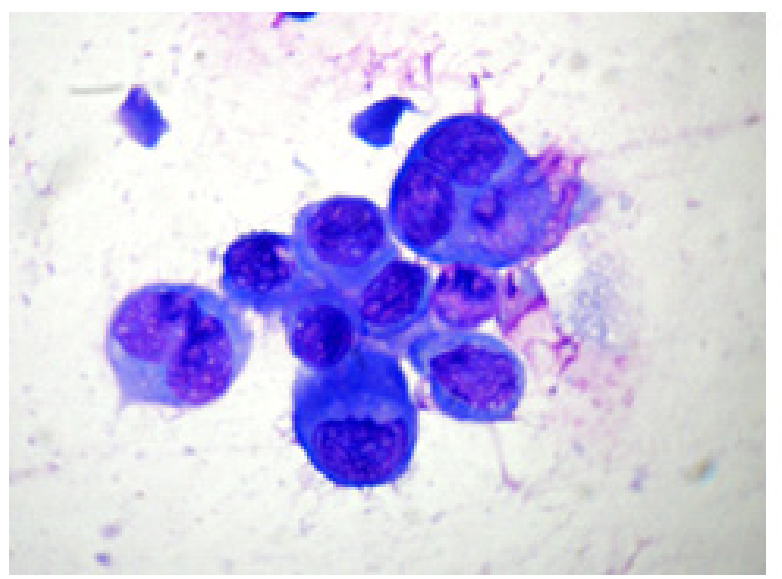

A

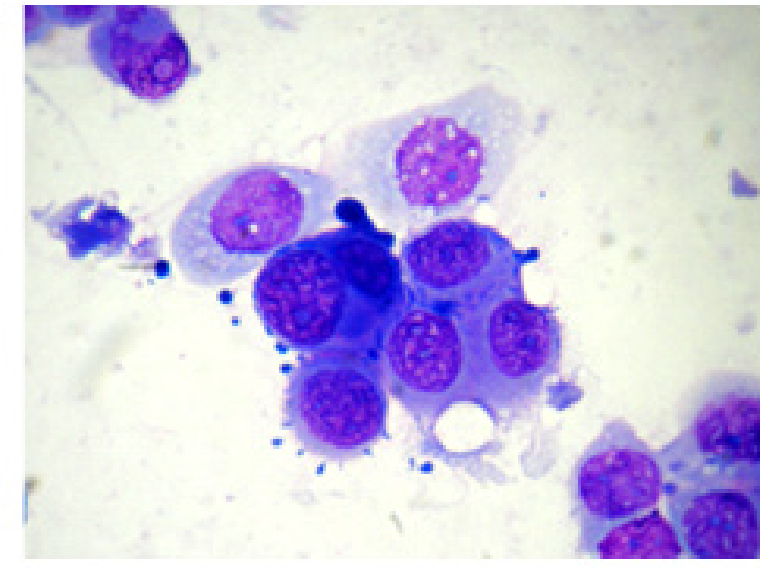

B

Fig. 8. German Shorthaired Pointer, 6 years old. FNA pulmonary mass. Bronchopulmonary adenocarcinoma. A. Group of neoplastic epithelial cells, with anisocytosis, anisokaryosis, high N/C ratio, inequal distribution of chromatin, bi- and trinucleated cells. B. Anisokaryosis in one of the binucleated cells, multiple and inequal nucleoli all cells. MGG, x 1000. 
there are no morphologic criteria that clearly distinguish between reactive mesothelial cells and cells from malignant neoplasms (Morrison and DeNicola, 1993).

The diagnosis of acute lymphoblastic leukemia was established with certainty by cytological examination of a blood sample in a 12 years old Collie female, with a total number of white blood cells of $104.3 \times 10^{3} / \mathrm{mm}^{3}$. The lymphocytes predominated $(65.3 \%)$ in blood and atypical lymphoblasts, prolymphocytes and frequent mitoses were observed (Fig. 10).

Neoplastic effusions from 9 cats $(4$ males and 5 females), aged 2 to14 years were, as in dogs, diagnosed with certainty in a lower proportion (3/9), 2 being identified as pulmonary adenocarcinoma with intrapleural exfoliation, and one hemophagocytic histiocytic sarcoma with intrapericardial exfoliation. For the remaining effusions, cytology oriented the diagnosis to one hepatic adenocarcinoma, with differential diagnosis to feline infectious peritonitis (FIP) being required and five pulmonary metastases of neoplasms with different locations (4 mammary neoplasms, 1 axillary lymphoma). The sero-hemorrhagic and hemorrhagic appearance was revealed in only 5 of the 9 examined effusions. In terms of the TNC, 5 were transudates (1.6 to $5.65 \times 10^{3}$ nucleated cells $/ \mathrm{mm}^{3}$ ), and 4 exudates (11.0 to 12.7 nucleated cells $\times 10^{3} / \mathrm{mm} 3$ ). In a 14 years old cat, with a total number of blood leukocytes of $72.1 \times 10^{3} / \mathrm{mm}^{3}$, has been established based on blood cytology (atypical myeloid cells with malignant characteristics), the diagnosis of myelogenous leukemia. Of the cytology malignancy criteria (Tab. 3), pleomorphism, anisocytosis with common aspects of cell gigantism,

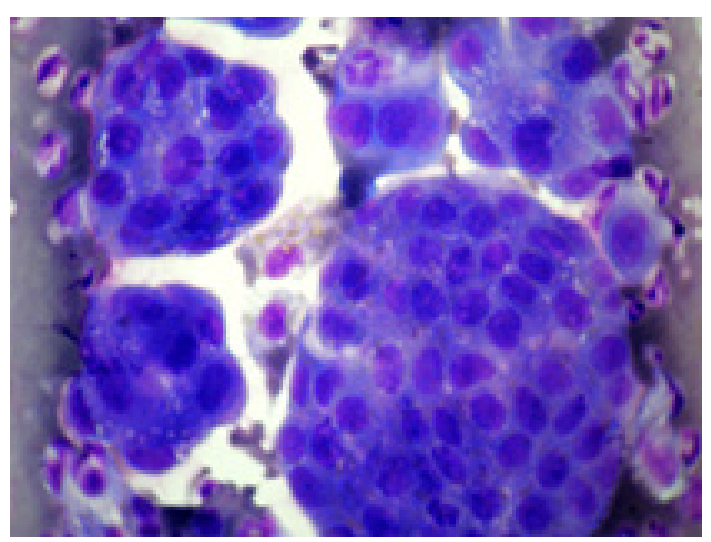

A

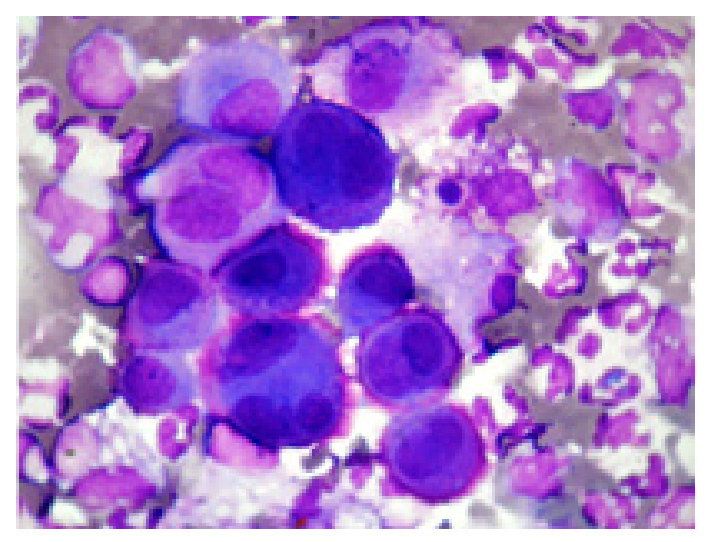

B

Fig. 9. Dog, female, cross bread, 14 years old. Pleural effusion (thoracocentesis). Pleuropulmonary adenocarcinoma/mesothelioma. A. Group of neoplastic cell with unknown origin, anisocytosis, anisokaryosis, high N/C ratio; associated imflammatory process. B. Anisokaryosis, multiple nuclei, dense chromatin, undistinguishable nucleoli. MGG, x 1000.

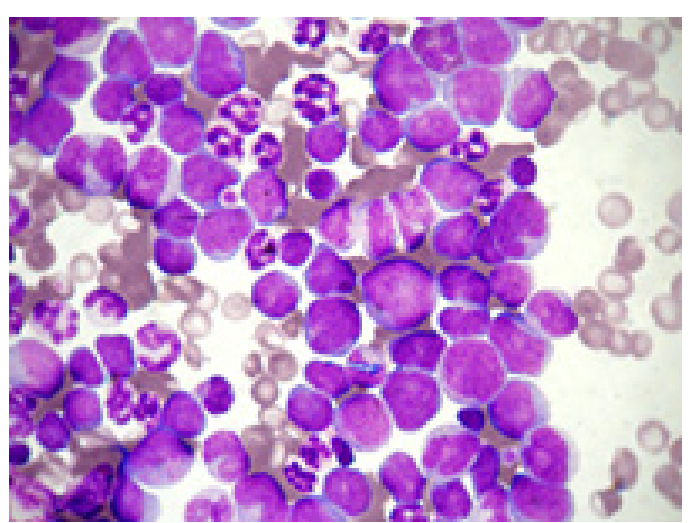

A

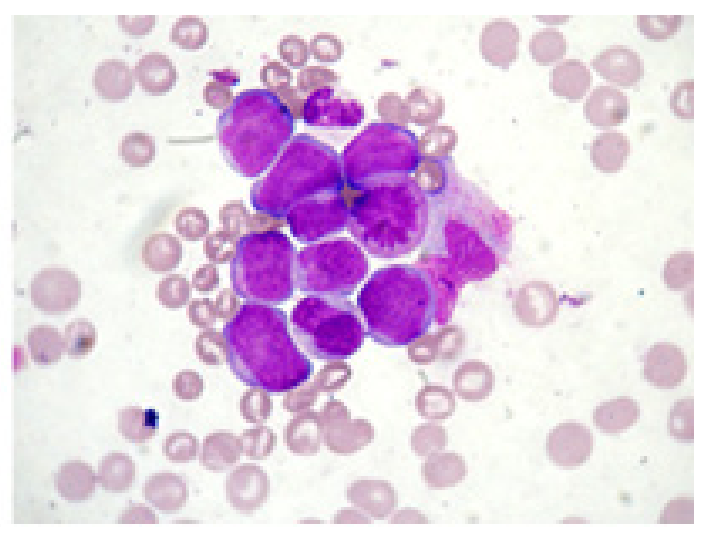

B

Fig. 10. Collie, 6 years old, F. Blood. Lymphoblastic leukemia. A. Lymphoblasts and prolymphocytes, two mitoses center. B. Atypical lymphoblasts, one mitosis. MGG, x 1000. 
anisokaryosis and the presence of macronucleoli were the most common features observed in the cytologic evaluation of feline effusions (7/10), followed by multinuclearity, densification and uneven distribution of nuclear chromatin (4/10). As with canine effusions, frequent mitoses cases were rare $(2 / 10)$, but unlike dogs, in cats were observed atypical and aberrant mitoses (2/10).

\section{CONCLUSION}

Taking into account the nuclear criteria of cell malignancy assessment, in this study were diagnosed by FNAC of the solid superficial masses 3 cutaneous mastocytomas (one hypogranular with lymphonodular metastatis, and 2 hypergranular mastocytomas), a mammary adenocarcinoma and a liposarcomain dogsand two subcutaneous sarcomas (one osteosarcoma and one hemangiosarcoma) in cats. Cytological diagnosis was definitive in all cases.

FNAC of generalized (2) and localized (2) lymphadenopathy cases provided a diagnosis of lymphoblastic lymphoma in $2 / 3$ of the dogs while in cats the only case of suspected lymphosarcoma required differential diagnosis to liposarcoma, post vaccinal sarcoma and fibrosarcoma.

FNAC of deep neoplastic masses (7) and liquids (18) allowed to establish definite diagnosis of pulmonary adenocarcinoma (one dog and two cats), osteosarcoma ( 2 dogs), pericardial hemangiosarcoma (one dog) and pericardial histiocytic sarcoma (one cat).

In neoplasm affected dogs, the malignant cytological diagnosis was definitive in $52,2 \%$ of the cases and uncertain in $47.8 \%$, while in cats, accurate diagnosis established by cytology has been noted in only $40 \%$ of cases, while the other $60 \%$ required complementary investigations. Neoplasia associated lesions were consistent with hemorrhagic lesions in $50 \%$ of cases and inflammation and necrosis in the rest of $55.3 \%$.

The results of this study confirmed FNAC as a reliable and useful diagnostic procedure for neoplastic masses. Even though FNAC has a limited value in determining the cellular origin of neoplastic masses or effusions, it often provides a definitive diagnosis or can narrow the list of differentials.

\section{REFERENCES}

1. Allen SW, Prasse KW, Mahaffey EA (1986). Cytologic Differentiation of Benign from Malignant Canine Mammary Tumors. Vet Pathol 23:649-655.
2. Barger A, Graca R, Bailey K, Messick J, De Lorimier LP, Fan T, Hoffmann W (2005). Use of Alkaline Phosphatase Staining to Differentiate Canine Osteosarcoma from Other Vimentin-positive Tumors. Vet Pathol 42:161-165.

3. Blackwood SM, Buracco P, De Vos JP, De Fornel-Thibaud P, Hirschberger J, Kessler M, Pastor J, Ponce F, Savary-Bataille K, Argyle DJ (2012). European consensus document on mast cell tumours in dogs and cats. Blackwell Publishing Ltd, Veterinary and Comparative Oncology, 10(3): e1-e29.

4. Cakir E, Demirag F, Aydin M, Unsal E (2009) Cytopathologic differential diagnosis of malignant mesothelioma, adenocarcinoma and reactive mesothelial cells: A logistic regression analysis. Diagn Cytopathol, 37(1):4-10.

5. Colomo L, Loong F, Rives S, Pittaluga S, Martínez A, LópezGuillermo A, Ojanguren J, Romagosa V, Jaffe ES, Campo E (2004). Diffuse Large B-cell Lymphomas with Plasmablastic Differentiation Represent a Heterogeneous Group of Disease Entities. Am J Surg Pathol 28:736-747.

6. Cowell RL, Tyler RD, Meinkoth JH (1998). Diagnostic Cytology and Hematology of the Dog and Cat. 2nd Ed, Mosby Inc, St. Louis, 211-230.

7. Dey P (2007). Time for evidence-based cytology. CytoJournal [serial online] 4:1. Available from: http:// www.cytojournal.com/text.asp?2007/4/1/1/41222.

8. Frable WJ (1983) Thin Needle Aspiration Biopsy. Saunders, Philadelphia, 13-15.

9. Meachem MD, Burgess HJ, Davies JL, Kidney BA (2012). Utility of nuclear morphometry in the cytologic evaluation of canine cutaneous soft tissue sarcomas. Journal of Veterinary Diagnostic Investigation 24(3):525-530.

10. Menard M, Fontaine M, Morin M (1986). Fine Needle Aspiration Biopsy of Malignant Tumors in Dogs and Cats: A Report of 102 Cases. Can Vet J 27(12):504-510.

11. Meyer DJ, Harvey JW (1998). Veterinary Laboratory Medicine, Interpretation and Diagnosis. Second Ed, WB Saunders Company, USA.

12. Morrison WB, DeNicola DB (1993). Advantages and disadvantages of cytology and histopathology for the diagnosis of cancer. Semin Vet Med Surg (Small Anim) 8:222-227.

13. Murakami Y, Tateyama S, Rungsipipat A, Uchida K, Yamaguchi R (2000). Immunohistochemical Analysis of Cyclin A, Cyclin D1 and P53 in Mammary Tumors, Squamous Cell Carcinomas and Basal Cell Tumors of Dogs and Cats. J Vet Med Sci 62(7): 743-750.

14. North S, Banks T (2009). Small animal oncology: an introduction. Saunders Elsevier (electronic resource), New York.

15. Radin MJ, Wellman ML (2001). Interpretation of canine and feline cytology. Gloyd Group Incorporated, Wilmington.

16. Sharkey LC, Seelig DM, Overmann J (2014). All lesions great and small, part 1: Diagnostic cytology in veterinary medicine. Diagn Cytopathol 42:535-543.

17. Sharkey LC, Wellman ML (2011). Diagnostic cytology in veterinary medicine: a comparative and evidence-based approach. Clin Lab Med 31(1):1-19.

18. Wellman ML (1990). The cytologic diagnosis of neoplasia. Vet Clin North Am Small Anim Prac 20:919-937. 